\title{
Composting of sewage sludge with solid fraction of digested pulp from agricultural biogas plant
}

\author{
Wojciech Czekała ${ }^{1}$, Jacek Dach $^{1}$, Jacek Przyby1 ${ }^{1}$, Jakub Mazurwiekiwcz ${ }^{1}$, Damian \\ Janczak $^{1}$, Andrzej Lewicki ${ }^{1}$, Anna Smurzyńska ${ }^{1}$, Kamil Kozłowski ${ }^{1}$ \\ ${ }^{1}$ Institute of Biosystems Engineering, Poznan University of Life Sciences, ul. Wojska Polskiego 28, \\ 60-637 Poznan, Poland
}

\begin{abstract}
Sewage sludge management is an important element of environmental protection. Composting and anaerobic digestion are the biological conversion methods for sewage sludge management. Mass and volume reduction is a result of a properly composted process. Solid fraction of digested pulp can be use as co-substrate, because it is good structural material. The aim of the study was to determine the possibility of composting sewage sludge with a solid fraction of digestate. The compost mix consisted of 25 kilograms of sewage sludge and 20 kilograms solid fraction of digestate in fresh mass. The experiment was carried out in laboratory conditions. Bioreactors of $165 \mathrm{dm}^{3}$ volume were used. The experiment included two stages. Stage I took place in bioreactors and lasted until the cooling phase of the compost was complete. Stage II included compost maturation for a period of eight months (to 287 day of composting). The reduction of mass obtained at the end of Stage I amounted $30.2 \%$. At the end of Stage II, it was $86.7 \%$ relative to the initial weight of the compost. The maximum value of temperature was $75.1{ }^{\circ} \mathrm{C}$. Studies have shown that sludge with a solid fraction of digestate can be a suitable substrate for composting with sewage sludge.
\end{abstract}

\footnotetext{
Abbreviations

$\mathrm{AD}$ - anaerobic digestion

DM - dry matter

FM - fresh matter

$\mathrm{MM}$ - mineral matter

$\mathrm{OM}$ - organic matter in Total Solids

$\mathrm{SF}$ - solid fraction of digested pulp

SL - sewage sludge
} 


\section{Introduction}

One of the most important environmental issues is the management of waste, including by-products of wastewater treatment processes such as sewage sludge (SL) $[1,2]$. Management of waste can take place using technologies compatible with sustainable development [3]. SL can be a problematic product for environment and requires management [4]. The primary reason is the amount of their formation and the content of odorogenic and harmful substances [5]. Therefore, it is necessary to look for technologies that will help them to be used for the benefit of the environment [6]. The most commonly management method of SL in last years was storage. Legal regulations that entered into force on January 1, 2016 prohibit the storage of SL. There is an order for sewage treatment plants to take measures to manage them in a way that is safe for the environment [7].

Composting and anaerobic digestion (AD) can be mentioned as part of the biological conversion process $[8,9]$. Composting is a controlled process of aerobic decomposition of organic matter with microorganisms, carried out in prisms or reactors [10]. Among the advantages of this method are the significant reduction in the weight and volume of composted mixtures and the final product, compost, which is an organic fertilizer [11]. SL is a substrate often used for the compost production [12,13]. This is largely due to the high degree of hydration and high nitrogen content. By adjusting the composition e.g. by adding straw it is possible to create the right proportion of substrate.

Methane fermentation takes place at sewage treatment plants, landfills and in the agriculture biogas plants [14]. In each of these cases, biodegradation of the substrates rich in organic matter occurs. The main product of the anaerobic digestion is biogas $[15,16]$. It is a mixture of gases, dominated by methane and carbon dioxide. Ammonia, hydrogen sulphide, hydrogen and other gases are present in smaller amounts. The second product is digested pulp (digestate), which is a residue from the decomposition process [17]. Digestate is mainly composed of mass of non-fermented compounds and bacterial biomass. Its quantity is closely related to the mass of the feedstock to the biogas plant. However, chemical composition, is largely conditioned by the type of substrates used in the biogas production process. The digested pulp is in the liquid form. Dry matter is usually 2 to $10 \%$. An important element in the digestate management is the separation process [18]. The result of the process are at least two fractions - solid and liquid [19]. Due to its abundance in organic matter, nitrogen and high humidity, it is possible to select the appropriate proportion of the composted mixture. The produced compost is an environmentally safely product and is desirable due to its fertilizer properties [20].

Considering the high volume of nitrogen in SL in on the one hand, and the SF in carbon on the other, it is possible to use them in the composting process. is As a result of oxygen decomposition processes compost hygienisation occurs. This is an important aspect of this process, since sludge is often a source of microbiological contaminants and helminths' eggs.

The purpose of the study was to determine the possibility of composting SL in a mix with a SF. The paper shows the origin and properties of the substrates used for composting, presents composting methodology and discusses the changes related to the particular parameters during composting. Moreover, the authors have done the discussion to compare the results of their own research with those obtained by other scientists. 


\section{Methodology}

\subsection{Substrates and composting mixtures}

SL used in the experiment came from one of the wastewater treatment plants near Poznan. The substrate was dehydrated using presses. Dehydrated municipal substrate was composted with a SF of the digested pulp from an agricultural biogas plant, located in Poland. Primarily corn silage, fruit pulp and distillery were used for the production of biogas in this installation. The compost mix consisted of 25 kilograms SL and 20 kilograms of SF in fresh mass. The dry weight of the SL was $14.56 \%$ and the SF was $32.52 \%$. The organic matter content in dry matter was $75.58 \%$ for sludge and $92.94 \%$ for digested pulp, respectively. During composting the temperature changes, carbon dioxide emissions, dry matter and organic matter, $\mathrm{pH}$, conductivity and bulk density were monitored (tab. 1).

Table 1. Participation and selected properties of the components used in the composting process.

\begin{tabular}{|c|c|c|c|c|c|}
\hline \multirow{2}{*}{ Substrates } & \multicolumn{4}{|c|}{ Properties } & \multirow{2}{*}{$\begin{array}{c}\begin{array}{c}\text { Participation } \\
\text { of substrates }\end{array} \\
\text { FM } \\
{[\%]}\end{array}$} \\
\hline & $\begin{array}{l}\text { DM } \\
{[\%]}\end{array}$ & $\begin{array}{l}\text { OM } \\
{[\%]}\end{array}$ & $\begin{array}{l}\text { pH } \\
{[-]}\end{array}$ & $\begin{array}{c}\text { cond. } \\
{\left[\mathrm{mS} \cdot \mathbf{c m}^{-1}\right]}\end{array}$ & \\
\hline SF & 32.52 & 92.94 & 9.07 & 1.27 & 20 \\
\hline SL & 14.56 & 75.58 & 7.09 & 0.24 & 25 \\
\hline
\end{tabular}

The nitrogen content in the compost mixture was $24.82 \mathrm{~g} \cdot \mathrm{kg}^{-1} \mathrm{DM}$ and phosphorus $16.66 \mathrm{~g} \cdot \mathrm{kg}^{-1} \mathrm{DM}$. The experiment included two stages. Stage I took place in bioreactors and lasted until the cooling phase of the compost was complete. Stage II included compost maturation for a period of eight months (to 287 day of composting).

\subsection{System for laboratory composting}

The experiment was carried out in laboratory conditions in the Laboratory of Ecotechnologies (Poznan University of Life Sciences). Bioreactors of $165 \mathrm{dm}^{3}$ volume were used for the experiment equipped with equipment for monitoring the decomposition of organic materials in aerobic and anaerobic conditions (fig. 1). Due to unique construction it is possible to continuously control the process going on inside the reactor. 


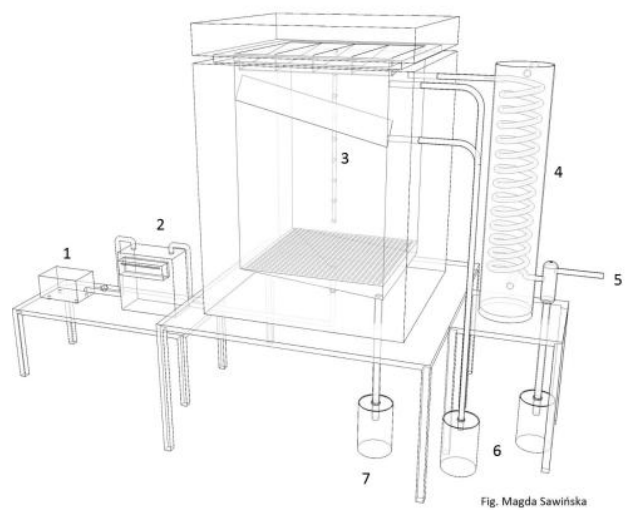

Figure 1. Schematic diagram of the system for laboratory composting 1 - air supply pomp, 2 - flow meter and flow regulator, 3 - chamber of reactor, 4 - air cooler, 5 - cold water, 6,7 - condensate and leachate collectors.

\subsection{Composting process}

During the experiment the air flow was regulated in the range of 0.8 to $2.7 \mathrm{dm}^{3} \cdot \mathrm{min}^{-1}$. The initial value of the air injected into the chamber was $2.5 \mathrm{dm}^{3} \cdot \mathrm{min}^{-1}$. Twice a day correctness was checked by rotameter. When approaching $5 \%$ oxygen in the air, the airflow was increased in order to prevent the occurrence of anaerobic conditions.

\subsection{Physical and chemical analysis}

In order to investigate physico-chemical parameters changes of the compost, samples were taken at the beginning, during the opening of the chambers (turning) and at the end of the experiment. Turning consisted of an opening of the bioreactor and mixing of the total contents of the chamber to aerate the compost and improve the structure of the composting material. The material for analysis was taken from the five different places in chamber and averaged sample was created. At the beginning and at the end of the experiment as well as during the turning, the mass and volume changes measurements were made using a laboratory scale. This allowed to determine the weight loss and volume during the experiment. Based on the changes in the tested parameters the bulk density of fresh compost was calculated.

The construction of the reactors allowed to collect gravity leaks from the compost. Special cooling system allows to condensate the vapor escaping from the chamber and from the radiator. DM of samples was determined by drying method at $105^{\circ} \mathrm{C}$ for $24 \mathrm{~h}$. Dried samples (each in three replicates) were incinerated to define $\mathrm{OM}$ and MM. Organic matter was determined in the furnace (temp. $550^{\circ} \mathrm{C}, 3 \mathrm{~h}$ ). Measurement was done in triplicates. Measurement of $\mathrm{pH}$ and conductivity was done using Elmetron CX-401 multifunction device. 


\subsection{Gaseous measurements}

During the composting process, air from the compost chambers was tested using a GeoTech GA5000 gas analyzer. The device allowed analysis of five gases in the concentration range: $\mathrm{CH}_{4}$ from 0 to $100 \%, \mathrm{CO}_{2}$ from 0 to $100 \%, \mathrm{O}_{2}$ from 0 to $25 \%, \mathrm{NH}_{3}$ from 0 to $1000 \mathrm{ppm}, \mathrm{H}_{2} \mathrm{~S}$ from 0 to $10000 \mathrm{ppm}$. Once a week, calibration of gas analyzer was done.

\subsection{Temperature measurement}

Temperature measurement was done using stick that tests a temperature of 20 centimetres from the bottom of the chamber. These measurements were recorded on the hard disk of the computer every 8 hours.

\section{Results}

\subsection{Characteristics of physical and chemical parameters changes}

The mass reduction obtained at the end of Stage I amounted $30.2 \%$. At the end of Stage II, it was $86.7 \%$ relative to the initial weight of the compost. This was due to the evaporation of water and the reduction of organic matter. After maturation, the dry matter content was $85.63 \%$.

The highest content of OM occurred on the first day of the experiment $-93.45 \%$. After turning, its content decreased to $81.38 \%$, and at the end of Stage I was $73.32 \%$ (tab. 2). During maturation of compost (over five months), the OM level was slightly changed eventually reaching $74.72 \%$ on two hundred nineteenth day.

Bulk density increased from $444 \mathrm{~kg} \cdot \mathrm{m}^{-3}$ at the beginning of the experiment to $557 \mathrm{~kg} \cdot \mathrm{m}^{-}$ ${ }^{3}$ (34 day) and $620 \mathrm{~kg} \cdot \mathrm{m}^{-3}$ on the sixty-nine day. Along with the duration of the process, the $\mathrm{pH}$ has changed from 7.65 to 8.5 (34 days) to 8.7 (51 days). At the end of Stage I (69 days), the level was 7.53. The maturation phase contributed to a decrease in the reaction, reaching a value of 6.55 . Conductivity increased from $0.79 \mathrm{mS} \cdot \mathrm{cm}^{-1}$ at the beginning of the experiment to $3.88 \mathrm{mS} \cdot \mathrm{cm}^{-1}$, an increase of $391 \%$.

Table 2. Selected compost properties during the process

\begin{tabular}{|c|c|c|c|c|c|}
\hline & Phase of composting & Day & FM [kg] & $\begin{array}{c}\text { DM } \\
{[\mathbf{\%}]}\end{array}$ & $\begin{array}{c}\text { OM } \\
{[\mathbf{\%}]}\end{array}$ \\
\hline \multirow{3}{*}{ Compost } & Start & 0 & 45 & 32.67 & 93.45 \\
\cline { 2 - 6 } & Turning & 34 & 36.1 & 19.71 & 81.38 \\
\cline { 2 - 6 } & Finish of Stage I & 69 & 31.4 & 17.25 & 73.32 \\
\cline { 2 - 6 } & Finish of Stage II & 287 & 6.0 & 85.63 & 74.72 \\
\hline
\end{tabular}

\subsection{Temperature changes}

The temperature of the composted mixture during the experiment ranged between 18 and $75.1^{\circ} \mathrm{C}$. The maximum value defining the thermophilic phase was demonstrated on the third day of the experiment. On the thirty-fourth day of the experiment, when the compost temperature reached a similar level of ambient temperature $\left(22.6^{\circ} \mathrm{C}\right)$, turning was made. After this step, which was associated with oxygenation of the mixture, the temperature 
increased to a maximum of $54.7^{\circ} \mathrm{C}$. In the following days there was a gradual decline in temperature to the sixty-ninth day, which was the end of the composting process in chamber (fig. 2).

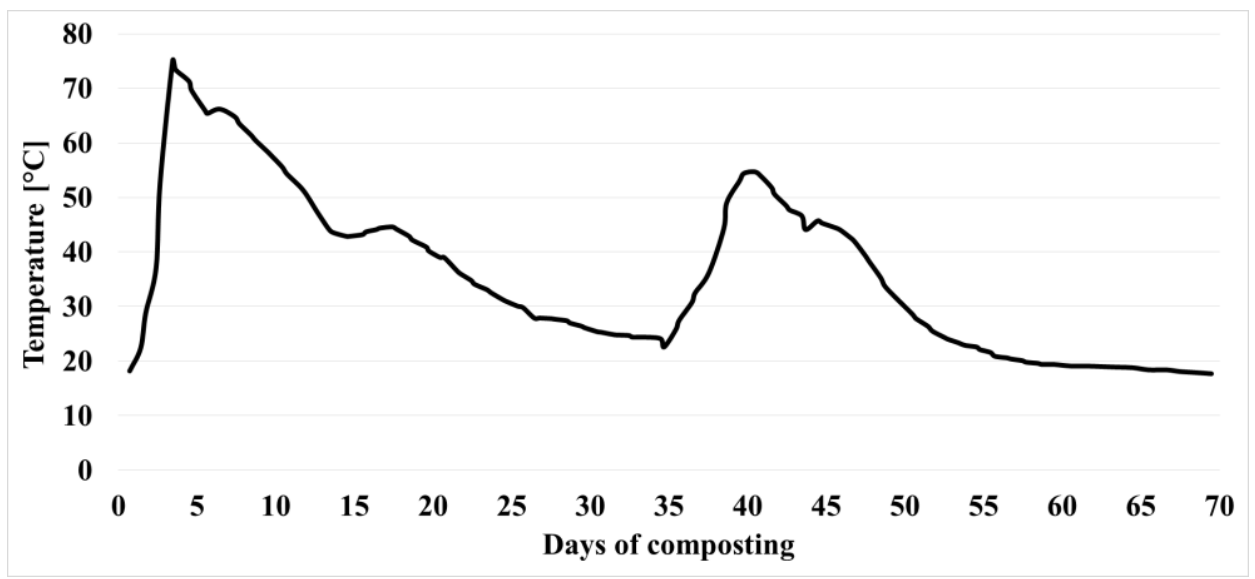

Figure 2. The temperature of the composted mixture during the experiment

\subsection{Gaseous emission changes}

The minimum concentration of oxygen at $9.1 \%$ level occurred on the third day of the study. Along with the compost being cooled down, the microbial activity has weakened, resulting in an oxygen increase to $17-20 \%$ level observed on the eleventh day, and lasted until the thirty-fourth. Decomposition of organic compost caused the decrease of oxygen content in the compost up to forty-first day. On forty-ninth day an oxygen stabilization started in chamber to the level of $20 \%$, until the end of Stage I of the experiment.

Carbon dioxide is generally negatively correlated with the concentration of oxygen during composting process. The increase in its concentration causes a direct proportional loss of oxygen, and their sum should be close to that occurring naturally in atmospheric air. Maximum values of carbon dioxide concentration of $11.7 \%$ were reported with the highest compost temperatures.

Emission of ammonia from the compost heap reached its maximum of $989 \mathrm{ppm}$ on the fourth day of the experiment, decreasing to less than $100 \mathrm{ppm}$ only on the eleventh day of composting. At the same time, there was no effect of turning on ammonia emissions. Methane and hydrogen sulfide levels were also monitored. Emission of these gaseous proves the presence of anaerobic conditions. Hydrogen sulfide was observed in both compartments only in the first days of composting, but its level was marginal. $\mathrm{H}_{2} \mathrm{~S}$ maximum emission occurred on the third day, $28 \mathrm{ppm}$.

Composting of SL with SF is relatively new. Straw is the most popular substrate for composting with SL. In the study [8] the research on composting SF as monosubstrate was carried out. The addition of sewage sludge in own research allowed to achieve higher temperatures (fig. 2). This was due to the supply of SL with significant amounts of nitrogen and improved $\mathrm{C} / \mathrm{N}$ ratio. Digestate was use in composting in research Franke-Whittle et al. [21]. The results of this authors also confirm the possibility of using digestate for composting. 


\section{Conclusion}

Studies have shown that SL with a SF can be a suitable substrate for composting. The proof of that are for example change of parameters and temperatures during the process. This was proven among others by the reduction of organic matter from $93.45 \%$ at the beginning of the experiment to $78.32 \%$ after 69 days of the process. Knowing that sewage sludge is rich in nitrogen, it is important to keep in mind the appropriate proportions between components so as to avoid excessive ammonia emissions.

\section{Information about sources of financing}

This work was supported by Human Capital Operational Programme, Sub-measure 8.2.2, co-financed by the European Union under the European Social Fund coordinated by Dr. Eng. Wojciech Czekała within the period of 2012-2013 (POKL 8.2.2/30-404-12/13) and 2013-2014 (PO KL 8.2.2/30-355-13/14). The research project "Scholarship support for doctoral students specializing in majors strategic for Wielkopolska's development".

\section{References}

1. J. Yuan, D. Chadwick, D. Zhang, G. Li, S. Chen, W. Luo, L. Du, S. He, S. Peng. Effects of aeration rate on maturity and gaseous emissions during sewage sludge composting. Waste Management 56, 403-410 (2016)

2. J.B. Bień, A. Grosser, E. Neczaj, M. Worwąg, P. Celary. Co-Digestion of Sewage Sudge with Different Organic Wastes - Review. Polish Journal of Environmental Studies Volume 2, 24-30 (2010)

3. D. Wojcieszak, J. Przybył, A. Lewicki, A. Ludwiczak, A. Przybylak, P. Boniecki, K. Koszela, M. Zaborowicz, K. Przybył, K. Witaszek. Use of neural image analysis methods in the process of determine the dry matter content in the compost. Proc. of SPIE Vol. 9631 963118-1 (2015)

4. J. Havukainen, M.T. Nguyen, L. Hermann, M. Horttanainen, M. Mikkilä, I. Deviatkin, L. Linnanen. Potential of phosphorus recovery from sewage sludge and manure ash by thermochemical treatment. Waste Management 49, 221-229 (2016)

5. M. Michałkiewicz, J. Jeż - Walkowiak, Z. Dymaczewski, M.M. Sozański. Dezynfekcja ścieków. Inżynieria Ekologiczna 24, 38-51 (2011)

6. M. Kacprzak, E. Neczaj, K. Fijałkowski, A. Grobelak, A. Grosser, M. Worwag, A. Rorat, H. Brattebo, A. Almås, B.R. Singh. Sewage sludge disposal strategies for sustainable development. Environmental Research 156, 39-46 (2017)

7. D. Kosicka-Dziechciarek, A. Wolna-Maruwka, J. Mazurkiewicz. The Danger of Pathogenic Organisms in Sewage Sludge and Methods of Their Reduction. Archives of Waste Management and Environmental Protection 17(4), 127-138 (2015)

8. W. Czekała, J. Dach, R. Dong, D. Janczak, K. Malińska, K. Jóźwiakowski, A. Smurzyńska, M. Cieślik. Composting potential of the solid fraction of digested pulp produced by a biogas plant. Biosystems Engineering 160, 25-29 (2017)

9. M. Cieślik, J. Dach, A. Lewicki, A. Smurzyńska, D. Janczak, J. PawlickaKaczorowska, P. Boniecki, P. Cyplik, W. Czekała, K. Jóżwiakowski. Methane fermentation of the maize straw silage under meso- and thermophilic conditions. Energy 115(2), 1495-1502 (2016) 
10. D. Janczak, K. Malińska, W. Czekała, R. Cáceres, A. Lewicki, J. Dach. Biochar to reduce ammonia emissions in gaseous and liquid phase during composting of poultry manure with wheat straw. Waste Management 66, 36-45 (2017)

11. M. Zaborowicz, D. Wojcieszak, K. Górka, S. Kujawa, R.J. Kozłowski, K. Przybył, N. Mioduszewska, P. Idziaszek, P. Boniecki. Determination of dry matter content in composted material based on digital images of compost taken under mixed visible and UV-A light. Proc. SPIE 10033, Eighth International Conference on Digital Image Processing (ICDIP 2016), 100332G (August 29, 2016) (2016)

12. M.C. Gutiérrez, A. Serrano, J.A. Siles, A.F. Chica, M.A. Martín. Centralized management of sewage sludge and agro-industrial waste through co-composting. Journal of Environmental Management 196, 387-393 (2017)

13. L. Meng, W. Li, S. Zhang, C. Wu, K. Wang. Effects of sucrose amendment on ammonia assimilation during sewage sludge composting. Bioresource Technology 210, 160-166. (2016)

14. R.L. Grando, A.M. de Souza Antune, F.V da Fonseca, A. Sánchez, R. Barrena, C. Font. Technology overview of biogas production in anaerobic digestion plants: A European evaluation of research and development. Renewable and Sustainable Energy Reviews 80, 44-53 (2017)

15. C. Zhao, X. Cui, Y. Liu, R. Zhang, Y. He, W. Wang, C. Chen, G. Liu. Maximization of the methane production from durian shell during anaerobic digestion. Bioresource Technology 238, 433-438 (2017).

16. K. Kozłowski, A. Lewicki, P. Sołowiej, M. Neugebauer, A. Smurzyńska, 2016. Usage of waste whey as mono-substrate in continuous fermentation process. Energy And Clean Technologies Conference Proceedings, SGEM Vol. III: 345350 (2016)

17. M.J. Stolarski, M. Krzyżaniak, K. Warmiński, J. Tworkowski, S. Szczukowski, E. Olba-Zięty E., Gołaszewski J. Energy efficiency of perennial herbaceous crops production depending on the type of digestate and mineral fertilizers. Energy 134, 50-60 (2017)

18. W. Czekała, S. Bartnikowska, A. Lewicka, A. Bugała, Z. Zbytek, A. Lewicki. Economic and energy efficiency of the solid biofuels produced from digested pulp. MATEC Web of Conferences 60, 04005 ICCBS (2016)

19. W. Czekała, J. Dach J. Przybył, P. Boniecki, A. Lewicki, P.C.R. Carmona, D. Janczak, H. Waliszewska. The energetic efficiency of solid fraction of digestate pulp from biogas plant in production of solid and gaseous biofuels - a case study of 1 MWel biogas plant in Poland. Proceedings of the 2nd International Conference on Energy \& Environment: Bringing Together Engineering and Economics: 547-553 (2015)

20. I. Sigurnjak, C. Vaneeckhaute, E. Michels, B. Ryckaert, G. Ghekiere, F.M.G. Tack, E. Meers. Fertilizer performance of liquid fraction of digestate as synthetic nitrogen substitute in silage maize cultivation for three consecutive years. Science of The Total Environment 599-600, 1885-1894 (2017)

21. I.H. Franke-Whittle, A. Confalonieri, H. Insam, M. Schlegelmilch, I. Körner. Changes in the microbial communities during co-composting of digestates. Waste Management 34, 632-641 (2014) 